\title{
PEMBERDAYAAN MASYARAKAT BERBASIS PENGEMBANGAN USAHA MIKRO, KECIL, DAN MENENGAH DI ERA REVOLUSI INDUSTRI 4.0
}

\section{(Community Empowerment Based on Micro, Small, and Medium Business Development in The Industrial 4.0 Revolution)}

\author{
Sri Peni Wastutiningsih ${ }^{1 *}$ dan Titis Puspita Dewi ${ }^{2}$ \\ ${ }^{1)}$ Fakultas Pertanian Universitas Gadjah Mada; Jalan Flora, Bulaksumur, 55281 \\ ${ }^{2)}$ Alumni Program Studi Penyuluhan dan Komunikasi Pembangunan Sekolah Pascasarjana Universitas Gadjah \\ Mada; Jalan Teknika Utara, Pogung, 55281 \\ *Email korespondensi: peni@ugm.ac.id dan titis.puspita.d@mail.ugm.ac.id
}

Received: 4 October 2018; Revised: 27 February 2019; Accepted: 13 March 2019

\begin{abstract}
Abstrak
Era revolusi 4.0 mendorong masyarakat untuk memanfaatkan internet sebagai wahana digital marketing. Masyarakat utamanya yang bergerak di bidang usaha mikro, kecil, dan menengah (UMKM) memiliki jangkauan pasar yang lebih luas dengan penggunaan internet atau pemasaran berbasis online lainnya. Hal tersebut mendorong akademisi sebagai bagian dari masyarakat untuk berperan aktif dalam menginisiasi, mendorong, dan mendampingi realisasi digital marketing tersebut, salah satunya telah dilakukan tim UGM di Desa Giriharjo, Kecamatan Panggang, Kabupaten Gunungkidul, Daerah Istimewa Yogyakarta. Masyarakat Desa Giriharjo memiliki potensi usaha pangan lokal maupun handycraft yang dapat dikembangkan melalui digital marketing. Penelitian ini merupakan penelitian kualitatif dengan tujuan mengidentifikasi fungsi dan dampak digital marketing yang telah diterapkan dalam proses pemberdayaan masyarakat. Adapun hasil penelitian menunjukkan adanya fungsi manifes berupa peningkatan jumlah penjualan dan omzet yang diperoleh pengusaha melalui digital marketing sedangkan fungsi latennya berupa perubahan gaya hidup masyarakat perdesaan yang menjadi konsumtif semenjak mengenal dunia internet.
\end{abstract}

Kata Kunci: pemberdayaan masyarakat, UMKM, digital marketing, fungsi sosial

\begin{abstract}
The Industrial Revolution 4.0 era forces people to use internet as a tool of digital marketing. Community engaging in micro, small and medium enterprises (MSMEs) or businesses has a broader market reach by utilizing internet or other online-based marketing method. This has encouraged academics as part of the community to play active roles in initiating, pushing, and accompanying in the realization of digital marketing, one of which has been done by UGM team in Giriharjo Village, Gunungkidul Regency, Yogyakarta. People in Giriharjo Village have potency of local food and handycrafts businesses that can be developed through digital marketing. This is a qualitative research with the aim of identifying the functions and impacts of digital marketing applied in the process of community empowerment. The results showed that there is a manifest function in the form of increasing the number of sales and omzet obtained by enterpreneurs through digital marketing, and the latent function is in the form of lifestyle changes in rural people who have become consumptive because of internet.
\end{abstract}

Keywords: community empowerment, MSMEs, digital marketing, social functions 


\section{PENDAHULUAN}

Era revolusi industri 4.0 telah mencapai masanya. Menurut Profesor Klaus Schwab, ekonom terkenal asal Jerman yang menulis dalam bukunya The Fourth Industrial Revolution menyatakan bahwa konsep ini telah mengubah hidup dan kerja manusia. Revolusi industri 4.0 ditandai dengan sistem cyberphysical. Sistem ini memungkinkan untuk mengumpulkan, mengakumulasi, dan menganalisis data digital serta tidak hanya menggambarkan yang dapat dilihat secara fisik tetapi dapat dilihat dalam dunia maya (Kim dan Park, 2017). Saat ini industri mulai menyentuh dunia virtual, berbentuk konektivitas antara manusia, mesin dan data, semua sudah ada di mana-mana, serta dikenal dengan nama internet of things (Tim Viva, 2018). Era ini mengarahkan masyarakat untuk hidup serba canggih dan benar-benar memanfaatkan internet sebagai media yang memberikan kemudahan. Salah satu perubahan yang disebabkan oleh era ini adalah munculnya bentuk pemasaran baru yaitu melalui digital marketing. Perkembangan teknologi digital telah mengubah pemasaran dari pengusaha UMKM yang semula dilakukan secara konvensional menjadi secara digital dengan memanfaatkan penggunaan media sosial dan penggunaan website untuk memasarkan produk mereka (Wardhana, 2015; Listiana et al, 2019).

Strategi digital marketing ini lebih prospektif karena memungkinkan calon pelanggan potensial untuk memperoleh segala macam informasi mengenai produk dan bertransaksi melalui internet. Digital marketing adalah kegiatan promosi dan pencarian pasar melalui media digital secara online dengan memanfaatkan berbagai sarana misalnya jejaring sosial dan platform penjualan produk atau jasa online. Digital marketing biasanya terdiri dari pemasaran interaktif dan terpadu memudahkan interaksi antara produsen, perantara pasar, dan calon konsumen. Di satu sisi, digital marketing memudahkan pengusaha dalam memantau hasil penjualan, keinginan, dan kebutuhan calon konsumen, di sisi lain calon konsumen juga dapat mencari dan mendapatkan informasi produk hanya dengan cara menjelajah dunia maya sehingga mempermudah proses pencarian sekaligus menemukan alternatif baik dari segi kualitas, harga, maupun lokasi penjualannya (Purwana dkk, 2017).

Masyarakat utamanya yang bergerak di bidang usaha mikro, kecil, dan menengah (UMKM) tentunya dapat memperluas jangkauan pasar melalui digital marketing. Dengan digital marketing, komunikasi dan transaksi dapat dilakukan setiap waktu/real time dan mengglobal atau mendunia. Melihat jumlah pengguna social media berbasis chat ini yang banyak dan semakin hari semakin bertambah membuka peluang bagi UMKM untuk mengembangkan pasarnya dalam genggaman smartphone (Pradiani, 2017). Selain itu, dari sisi finansial, digital marketing sangat menjanjikan untuk peningkatan laba usaha (Setiawati dan Widyartati, 2017).

Berdasar pada peluang dan manfaat digital marketing dipandang dapat mengatasi atau memberikan solusi atas masalah di bidang pemasaran yang dihadapi pengusaha UMKM yang umumnya terfokus pada tiga hal: (1) masalah persaingan pasar dan produk, (2) masalah akses terhadap informasi pasar, dan (3) masalah kelembagaan pendukung UMKM. Perkembangan teknologi digital memungkinkan para pelaku UMKM untuk memasarkan produknya secara online dan melakukan transaksi melalui sistem perbankan secara online pula (Wardhana, 2015). Hal ini didukung pula oleh mudahnya akses informasi dalam era revolusi 4.0.

Peluang dan manfaat digital marketing tidak serta-merta ditangkap dengan baik oleh masyarakat sehingga diperlukan peran berbagai pihak untuk menginisiasi pemanfaatan ini. Salah satu yang dilakukan tim UGM sebagai bagian dari masyarakat adalah dengan melaksanakan program pengabdian kepada masyarakat berbasis pengembangan desa binaan untuk memperkenalkan pemanfaatan digital marketing bagi wilayah yang telah memiliki potensi produk dan usaha. Program ini dilaksanakan di Desa Giriharjo, Kecamatan Panggang, Kabupaten Gunungkidul, Daerah Istimewa Yogyakarta yang memiliki sejumlah potensi pangan lokal dan handycraft yang dapat dikembangkan melalui digital marketing. Apabila masyarakat secara umum telah memahami adanya perubahan era digital menjadi era revolusi indutri 4.0 maka hal ini perlu dijadikan peluang agar memberikan nilai tambah bagi pengetahuan, ekonomi, dan kesejahteraan masyarakat. 
Pemasaran yang selama ini dilakukan masih bersifat konvensional. Beberapa pengusaha UMKM berbasis pangan lokal dan handycraft di wilayah Desa Giriharjo belum memanfaatkan digital marketing dengan baik. Alasan sederhananya adalah ketidaktahuan, ketidakpahaman, dan ketidakinginan menggunakan digital marketing yang dianggap masih belum terpercaya karena antara penjual dan pembeli tidak bertemu secara langsung. Oleh karena itu, sinergi antara tim UGM dan masyarakat utamanya pengusaha UMKM pangan lokal dan handycraft dilakukan agar pengusaha semakin melek dan berdaya dalam perkembangan era revolusi industri 4.0.

\section{METODE PENELITIAN}

Penelitian ini merupakan penelitian kualitatif dengan tujuan mengidentifikasi fungsi dan dampak digital marketing yang telah diterapkan dalam proses pemberdayaan masyarakat. Metode pengambilan data dilakukan dengan teknik observasi dan in depth interview. Adapun metode penentuan informan dilakukan secara snowball sampling kepada pengusaha UMKM berbasis pangan lokal dan handycraft melalui salah satu key informant Kepala Desa Giriharjo yang merupakan inisiator dan penanggungjawab utama kelompok usaha desa.

\section{HASIL DAN PEMBAHASAN}

Penelitian ini menggunakan teori fungsi sosial Robert K. Merton dimana terdapat fungsi manifes (fungsi nyata) dan fungsi laten (fungsi tersembunyi) terkait fungsi dan dampak digital marketing bagi pengusaha. Teori ini diharapkan dapat mengidentifikasi fungsi dan dampak penerapan digital marketing di lokasi penelitian.

Desa Giriharjo, Kecamatan Panggang, Kabupaten Gunungkidul, Provinsi Daerah Istimewa Yogyakarta merupakan desa yang menarik dengan potensi pangan lokal dan usaha handycraft yang dapat dieksplorasi lebih jauh. Desa ini berbatasan dengan Desa Selopamioro, Kabupaten Bantul (sebelah utara), Desa Giriwungu, Kabupaten Gunungkidul (sebelah selatan), Desa Giritirto (sebelah barat), dan Desa Girisuko (sebelah timur). Seluruh wilayah desa ini berbukit kapur dengan ketinggian 273 mdpl dan curah hujan 2000 mm. Jarak dengan ibukota kecamatan 0,05 kilometer, dengan ibukota kabupaten 38 kilometer, dengan ibukota provinsi/daerah 37 kilometer.

Desa Giriharjo terdiri dari 6 (enam) padukuhan. Akses menuju desa ini dapat melalui Jalan Imogiri ke arah barat, arah ke Gua Cerme. Desa Giriharjo merupakan salah satu akses menuju kawasan wisata Gua Cerme yang secara administratif telah dikelola secara penuh oleh Pemerintah Kabupaten Bantul (2011: 31) melalui Peraturan Daerah Nomor 04 Tentang Rencana Tata Ruang Wilayah Kabupaten Bantul Tahun 2010-2030. Topologi wilayah dengan bentang karst yang sulit menyimpan air atau diambil airnya dengan waktu yang cepat pun menambah permasalahan bagi masyarakat. Oleh karena itu, Desa Giriharjo rentan terhadap bencana kekeringan.

Berdasarkan Peraturan Kepala Badan Nasional Penanggulangan Bencana Nomor 07 Tentang Pedoman Pengelolaan Data dan Informasi Bencana Indonesia (2012: 3), kekeringan adalah "hubungan antara ketersediaan air yang jauh di bawah kebutuhan air untuk kebutuhan hidup, pertanian, kegiatan ekonomi, dan lingkungan. Kekeringan di bidang pertanian adalah kekeringan yang terjadi di lahan pertanian yang ada tanaman (padi, jagung, kedelai dan lain-lain) yang sedang dibudidayakan". Dampak serius pada kekeringan di bidang pertanian tersebut menyebabkan gagal panen akibat tanaman kekurangan air, berkurangnya sumber pangan bagi penduduk, serta hilangnya pendapatan masyarakat yang kesehariannya bekerja sebagai petani. Kekeringan di bidang pertanian ini menyebabkan masyarakat terutamanya keluarga petani perlu melakukan perubahan sosial dan penentuan alternatif pendapatan selain yang berasal dari usaha pertanian seperti optimalisasi sektor usaha lain. Salah satu sektor yang dapat dikembangkan adalah UMKM (Usaha Mikro, Kecil, dan Menengah).

Arah pengembangan sektor usaha yang direncanakan adalah pendayagunaan UMKM terkait pangan lokal dan handycraft sebagai potensi desa. Pangan lokal yang khas di sana adalah gula semut dan emping mlinjo yang dapat digunakan sebagai oleh-oleh khas pendukung wisata (ecotourism). Handycraft yang telah dibuat melalui BM Creative antara lain jam dinding, hanger kayu, kursi, meja, hiasan dinding, dan vas dari kayu panel yang diproduksi skala mikro di Dusun Banyumeneng I hingga III. Adapun wisata yang telah 
berkembang di Desa Giriharjo antara lain: telaga (Gandu, Dendeng, Waru, Benggolo), goa (Klego, Tlogo Sarang, Angkasa, Gebang Tinatar), bentang alam (Kaligedhe, Klego, Rancahan), mata air (Kali Gedhe, Tlogo Sarang, Jumbleng), serta puncak gardu pandang (Wates, Sobro). Melalui potensi wisata ini diharapkan pangan lokal dan handycraft dapat menjadi oleh-oleh khas desa. Selama ini pengelolaan wisata dan pengembangan UMKM berjalan dengan sendirinya. Dengan berkembanganya dunia digital, terdapat peluang untuk memanfaatkan dunia digital bagi pemasaran wisata maupun potensi UMKMnya.

Kegiatan pengabdian kepada masyarakat pengembangan desa binaan ini mengusung topik tentang pemanfaatan internet sebagai media promosi sekaligus informasi. Adanya potensi pangan lokal, handycraft, dan wisata diharapkan dapat didorong dengan penggunaan internet yang mumpuni oleh masyarakat setempat.

Seperti yang diketahui apabila tingkat melek internet dari total UMKM yang sekitar 57 juta pelaku, hanya 16 persen yang paham dan mampu mengembangkan bisnisnya melalui sistem online. Dengan demikian, lebih banyak UMKM bergerak dalam sistem offline (menunggu pembeli datang). Padahal pada era millenial seperti ini, segala hal dapat dijangkau dalam satu genggaman.

Pelaksanaan inisiasi pendayagunaan akses internet terkait pengembangan UMKM berbasis pangan lokal, handycraft, wisata, dan informasi kebencanaan dilakukan dengan melakukan sejumlah kegiatan mulai dari inisiasi pembentukkan kelompok UMKM agar masyarakat memiliki usaha yang lebih berdaya, pendampingan, dan pelatihan terkait peningkatan kapasitas dalam digital marketing, pemanfaatan internet, serta pembuatan website yang berfungsi sebagai penyedia informasi dan platform digital marketing.

Salah satu kendala mendasar di Desa Giriharjo terutamanya Dusun Banyumeneng IIII adalah sulitnya akses internet karena terdapat beberapa blank spot atau daerah di luar jangkauan pancaran gelombang elektromagnetik (Wijayanto, 2012). Pemerintah desa melalui informasi Kepala Desa Giriharjo, AEW (key informant) menyampaikan sulitnya akses internet akibat tidak terkoneksinya beberapa pemancar jaringan provider di wilayahnya. Selain akibat mayoritas wilayah yang berupa kawasan hutan juga adanya perbedaan ketinggian serta blank spot yang memang tidak memungkinkan adanya koneksi. Hal ini menjadi kendala utama pelaksanaan digital marketing di Dusun Banyumeneng I-III, Desa Giriharjo.

Menurut informasi, WaC (informan 2), salah satu pengelola BM Creative dengan usaha handycraft, kendala sinyal turut berpengaruh dalam penjualan mereka. Beberapa kali $\mathrm{WaC}$ dan tim berusaha membuat terobosan dengan memanfaatkan media sosial terutamanya WhatsApp dan Instagram untuk berjualan namun akibat akses internet yang terkadang sulit, menyebabkan pelayanan dan penjualan tidak dapat dilakukan secara real time. WaC merasakan pentingnya digital marketing pasca memanfaatkan website khusus UMKM dan informasi kebencanaan yang dibuat oleh tim UGM. Beberapa kali ia menerima pemesanan secara daring dengan jumlah yang cukup banyak, terlebih produk khas BM Creative yang memanfaatkan kayu panel cukup diminati di pasaran, terlebih kembali booming-nya desain rustic yang mengandalkan unsur kayu sebagai poin utamanya. BM Creative sebelumnya turut melakukan penjualan hingga taraf ekspor namun akibat kegagalan komunikasi dengan eksportir menyebabkan usaha mereka sempat mengalami gulung tikar hingga dibantu "bangkit" kembali melalui badan usaha milik desa (bumdes) yang dirintis Pemerintah Desa Giriharjo. Omzet penjualan produk per bulan meningkat 40-50 \% dibanding sebelum menggunakan digital marketing dan hanya berfokus pada penjualan dengan eksportir.

Menurut WaC (informan 2), digital marketing selain memberikan manfaat bagi pengembangan usaha juga turut memberikan informasi tentang tren produk yang saat ini digemari masyarakat. Tidak hanya itu, platform penjualan dan pembelian online seperti Shopee dan Bukalapak turut dimanfaatkan dalam memperluas jejaring penjualan sekaligus menjadikan $\mathrm{WaC}$ dan tim dapat berbelanja secara online untuk produk sejenis. Hal ini dilakukan untuk mengetahui kualitas yang diharapkan pasar penjualan handycraft. Melalui pembelian secara online dengan platform Shopee dan Bukalapak, WaC merasa cukup terbantu dan tidak lagi mengalami keraguan (terdapat kemungkinan ditipu) karena pembeli dapat menahan pembayaran ketika produk yang 
diterima cacat, belum sampai hingga waktu pengiriman yang ditentukan, atau tidak sesuai dengan gambar yang ditampilkan. Dengan demikian, pembelian contoh handycraft yang sedang in menjadi lebih aman, mudah, dan murah bergantung rekomendasi platform.

Lain halnya dengan Smy (informan 3) yang merintis usaha pangan lokal gula semut dan emping mlinjo. Menurutnya, digital marketing memberikan perubahan besar dalam usahanya. Selama ini Smy hanya memanfaatkan pemasaran dari mulut ke mulut atau menitipkan barang dagangannya di koperasi sekolah, toko kelontong, atau menjualnya di rumah. Pasca pendampingan dan pelatihan yang dilakukan tim UGM, Smy menemukan media baru dalam pemasaran produknya yang dianggap terlalu umum (keripik mlinjo) dan tidak menjual (gula semut). Awalnya terdapat keraguan, mengingat komputer dan internet merupakan hal baru. Kesulitan dalam akses dan keterbatasan sinyal seringkali menyulitkan Smy untuk mengakses website yang telah dibuat oleh tim UGM maupun membuka website Desa Giriharjo yang juga dimanfaatkan sebagai platform pengembangan usaha masyarakat.

Smy yang awalnya hanya mengenal beberapa bentuk sederhana pada pengemasan dan produk yang dijualnya kemudian mulai melakukan inovasi dengan mencoba bentuk baru yang dirasa lebih menjual seperti menambahkan beberapa perasa makanan (keju, barbeque, balado) untuk emping mlinjo yang dijualnya agar semakin laku di pasaran. Sejauh ini, Smy baru memanfaatkan platform digital marketing untuk melakukan penjualan dan mencari inovasi pengembangan produk, belum sampai memanfaatkannya sebagai salah satu alternatif pasar untuk memenuhi kebutuhan sehari-hari. Omzet penjualan per bulan pun mengalami peningkatan antara 10-20\% mengingat belum maksimalnya penggunaan internet dan masih adanya keraguan terhadap calon pelanggan.

Smh (informan 4) pun melakukan hal yang sama seperti Smy yang mulai memanfaatkan media baru sebagai digital marketing. Smh yang juga merupakan istri kepala Dusun Banyumeneng II, petani bawang merah, dan tergabung dalam kelompok pangan lokal Banyumeneng II menemukan platform penjualan melalui WhatsApp. Selama ini, WhatsApp yang dikenal sebagai media chatting kemudian beralih digunakan sebagai media pemasaran produk bawang merah (mentah) maupun olahan bawang merah seperti bawang merah goreng yang dikemas oleh kelompok pangan lokal Banyumeneng II.

Smh baru menyadari adanya manfaat lain dari media sosial pasca inisiasi dan pendampingan dari tim UGM terkait digital marketing produk pangan lokal. Omzet penjualan bawang merah mentah maupun olah per bulan meningkat 10-15 \%. Hal tersebut dipengaruhi oleh Smh yang masih mengalami kendala apabila terdapat beberapa nomor baru yang menghubunginya melalui WhatsApp untuk membeli produknya. Kepercayaan terhadap calon konsumen yang membeli secara daring seringkali masih belum dilakukan mengingat adanya sharing informasi mengenai penipuan berbasis online yang diterima oleh masyarakat. Tidak hanya itu, minimnya informasi tentang pengelolaan media sosial dan jaminan kepercayaan dari calon konsumen kepada pembeli menjadi pekerjaan rumah tersendiri mengingat masih "agak tertutupnya" masyarakat perdesaan terutamanya Dusun Banyumeneng yang secara geografis berada di wilayah perbatasan dan minim jaringan sinyal.

Berbeda dengan $\mathrm{Nv}$ (informan 5) yang sudah melakukan pemberian kepercayaan kepada penjual pada platform penjualan online Shopee. Nv sebagai salah satu pemudi desa penggerak pertumbuhan UMKM berbasis penjualan produk jadi seperti jilbab, tas, dompet, dan sandal memercayakan pemasok produknya melalui Shopee. Nv bersama dengan kelompok keagamaan yang dikelolanya saat ini telah melirik bisnis pangan lokal sebagai sumber pemasukan lain.

$\mathrm{Nv}$ tidak hanya melakukan pembelian secara daring melalui Shopee namun juga mulai menjual produk jadi maupun produk olahan pangan lokal kelompoknya ke dalam platform penjualan online. $\mathrm{Nv}$ awalnya ragu karena beberapa kali mengalami kasus penipuan namun kelamaan dari proses belajar dan dukungan pendampingan dari tim UGM, $\mathrm{Nv}$ dan kelompoknya mulai sering menggunakan website, WhatsApp, dan Instagram untuk melakukan penjualan. Omzet penjualan pun meningkat secara signifikan kurang lebih 60-70 \%. Menurut Nv, keuntungan yang diperoleh pun berlipat ganda hingga $200 \%$ (dapat dikatakan telah BEP, break even point atau balik modal). 
Wastutiningsih dan Dewi (2019): Pemberdayaan masyarakat berbasis UKM di era 4.0

Berdasarkan hasil penelitian, peneliti menyimpulkan dampak digital marketing untuk masing-masing informan dalam Tabel 1.

Pada penelitian ini, fungsi yang diharapkan atau fungsi manifes atau intended dapat dilihat pada informan 1 hingga 5 yang merasakan manfaat peningkatan jumlah penjualan dan adanya contoh produk yang sedang in serta dapat dibeli secara online sedangkan fungsi laten atau non intended adalah ketergantungan pembelian seperti yang terjadi pada informan 1 dan 5 yang memanfaatkan platform pembelian online seperti Shopee dan Bukalapak untuk membeli produknya. Beberapa produk mungkin dapat dibuat ataupun dibeli di sekitar wilayah Desa Giriharjo namun adanya tingkat kepercayaan yang tinggi terkait kualitas dan harga sesuai ulasan platform maka mereka menjadi lebih suka berbelanja online. Tidak hanya itu, digital marketing seringkali membawa dampak yang tidak dapat diduga sebelumnya seperti adanya kasus penipuan atau cyber crime yang saat ini marak dialami oleh pengusaha UMKM. Hal ini turut diyakini oleh informan 1, 3, dan informan 4. Oleh karena itu, dibutuhkan pemahaman, pendampingan, dan penjelasan mengenai fungsi serta dampak digital marketing secara lebih komprehensif untuk menghindari fungsi nonintended digital marketing. Simpulan terkait fungsi manifes dan laten yang dialami oleh informan ditampilkan dalam Tabel 2.

Tabel 1. Dampak Digital Marketing

\begin{tabular}{|c|c|c|c|}
\hline $\begin{array}{l}\mathbf{N} \\
\text { o. }\end{array}$ & $\begin{array}{l}\text { Pengetahu- } \\
\text { an }\end{array}$ & Omzet & Jejaring \\
\hline 1. & Meningkat & - & $\begin{array}{l}\text { Semakin bertambah } \\
\text { dan masyarakat } \\
\text { merasakan dampak } \\
\text { yang signifikan }\end{array}$ \\
\hline 2. & $\begin{array}{l}\text { Meningkat } \\
\text { dan ada } \\
\text { informasi } \\
\text { baru }\end{array}$ & $\begin{array}{l}\text { Meningkat } 40-50 \\
\% \text { dan hanya } \\
\text { berfokus pada } \\
\text { penjualan dengan } \\
\text { eksportir }\end{array}$ & Semakin bertambah \\
\hline 3. & Meningkat & $\begin{array}{l}\text { Meninhgkat 10-20 } \\
\% \text { (belum } \\
\text { maksimal) dan } \\
\text { masih adanya } \\
\text { keraguan terhadap } \\
\text { calon pelanggan. }\end{array}$ & - \\
\hline 4. & Meningkat & $\begin{array}{l}\text { Meningkat } 10-15 \\
\%\end{array}$ & $\begin{array}{l}\text { Semakin bertambah } \\
\text { dengan } \\
\text { memanfaatkan } \\
\text { informasi dari orang } \\
\text { yang telah dikenal } \\
\text { melalui WhatsApp }\end{array}$ \\
\hline 5. & Meningkat & $\begin{array}{l}\text { Meningkat secara } \\
\text { signifikan kurang } \\
\text { lebih } 60-70 \%\end{array}$ & $\begin{array}{l}\text { Semakin bertambah } \\
\text { karena banyak } \\
\text { platform yang } \\
\text { digunakan }\end{array}$ \\
\hline
\end{tabular}

Tabel 2. Fungsi Manifes dan Laten Digital Marketing UMKM Pangan Lokal dan Handycraft

\begin{tabular}{ll}
\hline \multicolumn{1}{c}{ Fungsi Manifes } & \multicolumn{1}{c}{ Fungsi Laten } \\
\hline $\begin{array}{l}\text { Terdapat alternatif media } \\
\text { untuk melakukan }\end{array}$ & $\begin{array}{l}\text { Ketergantungan terhadap } \\
\text { platform pembelian tertentu } \\
\text { pemasaran produk }\end{array}$ \\
& $\begin{array}{l}\text { seperti Shopee dan } \\
\text { Bukalapak }\end{array}$ \\
\hline Peningkatan omzet dan & Adanya kemungkinan kasus \\
pengetahuan tentang tren & penipuan atau cyber crime \\
produk & yang menyebabkan \\
& rendahnya pemanfaatkan \\
& digital marketing pada \\
& informan 3 dan 4 \\
\hline Sumber: Analisis Peneliti, 2018
\end{tabular}

\section{KESIMPULAN}

Pengusaha UMKM berbasis pangan lokal dan handycraft di Desa Giriharjo, Kecamatan Panggang, Kabupaten Gunungkidul, Daerah Istimewa Yogyakarta memiliki potensi usaha yang telah dikembangkan melalui digital marketing. Pengusaha yang sudah menggunakan digital marketing mengatakan adanya peningkatan jumlah penjualan (fungsi manifest). Di samping itu juga ada alternatif di dalam memasarkan produknya. Adapun fungsi latennya berupa perubahan gaya hidup masyarakat perdesaan yang menjadi konsumtif semenjak mengenal dunia internet. Namun demikian di sisi lain muncul ketakutan terhadap terjadinya cyber crime terutamanya penipuan oleh calon pelanggan dalam digital marketing. Hal ini dapat diminimalisir dengan adanya pendampingan yang lebih lanjut dari tim pendamping agar dapat mengurangi fungsi laten yang mengikuti digital marketing.

\section{DAFTAR PUSTAKA}

Badan Nasional Penanggulangan Bencana (BNPB). 2012. Pedoman Pengelolaan Data dan Informasi Bencana Indonesia. (http://www.gitews.org/tsunami-

kit/en/E6/further_resources/national_level/ peraturan_kepala_BNPB/Perka\%20BNPB $\% 207-$

2012_Pedoman\%20Pengelolaan\%20Data \%20dan\%20Informasi\%20Bencana\%20In donesia.pdf, diakses 26 Februari 2018).Jonata, Willem. 2017. Tingkat Melek Internet Pada UMKM Masih Rendah. (Internet). (www.tribunnews.com/nasional/2017/05/1 7/tingkat-melek-umkm-pada-internet- 
Wastutiningsih dan Dewi (2019): Pemberdayaan masyarakat berbasis UKM di era 4.0

masih-rendah, diakses 26 September 2018).

Kim, Sung Hyun dan Park, SungBum. 2017. CPS (Cyber Physical System) based Manufacturing System. Jurnal Procedia Computer Science 122, pp. 518-524.

Listiana, I. Efendi, I. Mutolib, A. dan Rahmat, A. 2019. The behavior of Extension Agents in Utilizing Information and Technology to Improve the Performance of Extension Agents in Lampung Province. Journal of Physics: Conference Series, 1155 (012004): 1-9.

Pemerintah Kabupaten Bantul. 2011. Peraturan Daerah Kabupaten Bantul Nomor 04 Tahun 2011 Tentang Rencana Tata Ruang Wilayah Kabupaten Bantul Tahun 20102030.

(http://bappeda.bantulkab.go.id/data/hal/0/ 13/23/25-peraturan-daerah-kabupatenbantul-no-04-tahun-2011-tentang-rencanatata-ruang-wilayah, diakses 26 Februari 2018).

Pradiani, Theresia. 2017. Pengaruh Sistem Pemasaran Digital Marketing Terhadap Peningkatan Volume Penjualan Hasil Industri Rumahan. Jurnal Jibeka Volume 11 Nomor 2 Februari 2017 pp. 46-53

Purwana, Dedi; Rahmi; dan Aditya, Shandy. 2017. Pemanfaatan Digital Marketing Bagi Usaha Mikro, Kecil, dan Menengah (UMKM) di Kelurahan Malaka Sari, Duren Sawit. Jurnal Pemberdayaan Masyarakat Madani (JPMM) Volume 1 Nomor 1 Juli 2017.
Ritzer, George, 2007. Sosiologi Ilmu Pengetahuan Berpradigma Ganda. Jakarta: PT. Raja Grafindo Persada.

Setiawati, Ira dan Widyartati, Penta. 2017. Pengaruh Strategi Pemasaran Online Terhadap Peningkatan Laba UMKM. Jurnal Bingkai Manajemen yang diterbitkan melalui Seminar Nasional dan Call for Paper 2017 STIE Dharmaputra Semarang pp. 343-347 Mei 2017.

Tim Viva. 2018. 4 Tahap Revolusi Industri Sampai ke Era 4.0. (Online). (https://www.viva.co.id/ digital/digilife/1040470-4-tahap-revolusiindustri-sampai-ke-era-4-0, diakses 27 September 2018).

Wardhana, Aditya. 2015. Strategi Digital Marketing dan Implikasinya pada Keunggulan Bersaing UKM di Indonesia. Prosiding Seminar Nasional Forum Keuangan dan Bisnis IV Tahun 2015 pp. 327-337.

Wijayanto, Heri. 2012. Pemancar Televisi VHF Mengatasi Blank Spot di Tulakan Pacitan. Jurnal Ilmiah Multitek Indonesia Volume 6 Nomor 1 (2012).

\section{UCAPAN TERIMA KASIH}

Peneliti mengucapkan terima kasih kepada Direktorat Pengabdian kepada Masyarakat Universitas Gadjah Mada yang telah membiayai pelaksanaan Program Pengabdian kepada Masyarakat Berbasis Pengembangan Desa Binaan Tahun 2018 sehingga dapat terwujud tulisan ini. 